\title{
PENSAMENTO COMO MARGEM, LACUNA E FALTA: MEMORIA, TRAUMA, LUTO E ESQUECIMENTO
}

\author{
Paulo Endo
}





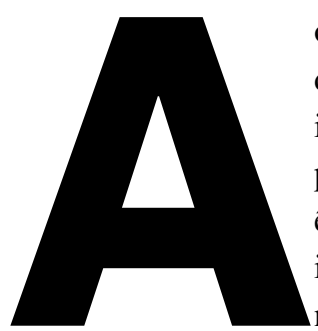

o lado da experiência do sobrevivente e dos impasses que se perpetuam nessa experiência - para sempre instalada no sujeito, na sociedade e na cultura -, mobilizam-se tentativas de figuração, representação e compreensão que, se, por um lado, não poderão capturar inteiramente essas heranças deixadas pelas violências, por outro se abrem para alguma restauração do pensamento diante do inominável. Trata-se dos conceitos que foram convocados nos debates sobre a memória social e hoje se impõem como noções-chave no vasto tema da memória social e política, no qual adquiriram sentido e notoriedade. Examinarei aqui, preliminarmente, e de modo ligeiro ${ }^{1}$, as experiências-conceito de trauma, luto, testemunho e a díade recordar/esquecer. Noções, conceitos ou palavras de ordem que foram absorvidos e, de certo modo, incorporados tanto nas pesquisas, debates e investigações sobre o tema, quanto nas lutas políticas em torno da preservação e revelação da memória e dos arquivos.

\section{O TRAUMA COMO MARCA INDELÉVEL DA DOR PSÍQUICA E COMO IMPOSIÇÃO IDEOLÓGICA NA CONSTRUÇÃO DO DISCURSO SOBRE A DOR}

O trauma se tornou uma ideia, conceito ou noção que passou para o lado das palavras de uso corriqueiro quando se fala em violações, violências e atrocidades cometidas entre os seres humanos. A palavra foi elevada em seu status e frequenta uma imensa quantidade de estudos sobre a memória com atravessamentos disciplinares muito prolífi$\cos ^{2}$. Deslindar a função desses usos - ou abusos - indica uma tarefa importante para evidenciar de que maneira aquilo que sobra e falta na experiência do trauma se abre e continua no campo político, social e intelectual em busca de forma e representação.

Herdado do conceito de trauma físico, que pode ser definido pela invasão e golpeamento de um agente externo sobre o corpo físico que, por efeito desse mesmo golpe, é lesionado, ferido ou machucado, o conceito de trauma psíquico pouco a pouco se tornou portador de outros matizes e exigiu outras inteligibilidades de maior complexidade, a reivindicar, portanto, maior exigência e cuidado por parte dos que dele se apropriam.

Nos estudos sobre a memória, o arcabouço conceitual que suporta fundamentalmente o conceito de trauma psíquico é fortemente influenciado pela psicanálise, mas tem sido pouco a pouco alterado em função dos debates uni e interdisciplinares, dos movimentos sociais e das inúmeras pesquisas que prosseguem em torno dos estudos sobre memória social, memória política, memória e identidade, memória coletiva, memória cultural, memória contida (contained memory) e dos estudos cerebrais sobre a memória.

A longa tradição de estudos psicanalíticos sobre o trauma, desde Freud, deu relevo e centralidade ao conceito de trauma jamais al-
PAULO ENDO

é psicanalista e professor do Instituto de Psicologia da USP e da Pós-Graduação Interdisciplinar em Humanidades, Direitos e Outras Legitimidades da FFLCH-USP.

O texto baseia-se em pesquisa que está sendo realizada com o fundamental apoio do Conselho Nacional de Pesquisa (CNPq) do Brasil.

1 Esses estudos fazem parte de uma pesquisa maior, envolvendo estudiosos brasileiros e argentinos, que ainda se encontra em estágio de preparação. As observações apresentadas aqui são, portanto, preliminares - o ensejo para a pesquisa - e ligeiras - ainda sem os elementos mínimos que permitam o aprofundamento suficiente do tema nessa etapa.

2 No vasto conjunto desses estudos, cito alguns que mereceram e merecerão destaquenopresente projeto e na presente investigação: Scarry, 1985; Felman \& Laub, 1992; Derrida, 2001 $2001 \mathrm{a}$; Agamben, 2005; Ricoeur, 2007; Teles et alii, 2009; Assman, 2011; Seligman-Silva, Ginzburg e Hardman, 2012; etc. 
3 Note-se que em um dos mais importantes manuais para a avaliação de casos de tortura, produzido interdisciplinarmente em 1999 e com a participação de organizações de direitos humanos de diversos países, a PTSD aparece como critério diagnóstico incorporado do $\mathrm{Ma}$ nual Diagnóstico e Estatístico de Doenças Mentais da Associação Americana de Psiquiatria (DSM IV). Apesar das ressalvas, o importante Protocolo de Istambul permaneceu refém de diagnósticos e elementos bastante clássicos do saber médico sem uma crítica suficiente. Cito: "Embora as principais queixas e achados mais comuns entre sobreviventes de tortura sejam extremamente diversos, geralmente relacionadosàs experiências da vida pessoal, contexto social, cultural e político, é prudente que o examinador se familiarize com as categorias mais comuns entre os sobreviventes de tortura e trauma" (Rauter 2002, p. 354) cançado até então. Porém, mesmo no interior do pensamento freudiano e do movimento psicanalítico, esse debate tornou-se por vezes obscuro e incerto (Endo, 2012), atrasando em boa parte desenvolvimentos ulteriores às primeiras formulações de trauma no pensamento freudiano (Leys, 1996; Endo, 2005).

Tais formulações psicanalíticas influenciaram uma determinada conceituação do testemunho (Seligmann-Silva, Ginzburg, Hardman, 2012), que as herdou, porém, ao mesmo tempo, possibilitaram (e permitiram) usos e abusos fora do campo reflexivo no qual tais conceitos são sucessivamente apresentados e revistos. Concomitantemente, o trauma continuou a ser disputado por outros campos e adquiriu fama e fortuna a partir de sua descrição na nosografia psiquiátrica, e do estatuto médico que lhe foi conferido com a amplamente difundida síndrome de estresse pós-traumático (post-traumatic stress disorder-PTSD).

Em muitos sentidos, a nosografia psiquiátrica propõe o oposto do que se formula nas investigações sobre a memória no campo das humanidades, isso porque sua "sindromização" permitiu um uso do conceito de trauma que abre o caminho para a individualização, a patologização e a judicialização da experiência do trauma como doença mental e, consequentemente, propôs formas de atenção e tratamento que tendem ou, ao menos, suportam ignorar a situação social e política que engendra a situação traumática e a reproduz (Burnett \& Thompson, 2012).

Diferentemente da literatura de testemunho, da produção testemunhal propriamente dita, expressa na forma de narrativas orais e escritas, e da presença do conceito de trauma em determinados debates no interior da teoria política (Agamben, 2005), o trauma como síndrome arrastou consigo certa formalização médica do conceito, sumamente estrita e individualizante, que fratura a compreensão do traumático alienando-o no sujeito psiquicamente particularizado, circunscrevendo-o em torno de seus sintomas e de seus tratamentos.

Quando transformada em doença mental
(PTSD), debilita, de certa forma, as possibilidades de politização e compreensão da situação traumática nos processos de luta por justiça diante dos tribunais, que frequentemente acatam o diagnóstico de PTSD como elemento objetivo na comprovação do dano sofrido por aqueles que foram vitimados por violações, no entanto, tendem a reconhecê-lo como dolo individual cuja reparação inclui os tratamentos e as indenizações.

Nos processos envolvendo a necessidade e a possibilidade de restauração, não raro, a avalização da categoria médica (PTSD) é sugerida para a aferição ou a constatação do dano, mesmo em cortes internacionais de direitos humanos ${ }^{3}$.

Determinados problemas e confusões em torno de definições, entretanto, não se concentram exclusivamente em eventuais divergências entre as definições e conceitos advindos do saber médico e aqueles, outros, definidos no campo das humanidades. É possível reconhecer divergências e imprecisões no uso banal e corriqueiro que se pode fazer do trauma, com finalidades politicamente orientadas 4 .

Do ponto de vista dos matizes e das consequências de violações e violências, a delimitação consequente do conceito de trauma é tão necessária quanto urgente. Isso devido a uma situação paradoxal que levaria ao empobrecimento da compreensão da experiência psíquica diante das situações extremas, caso se restringisse ao trauma, e permanecesse refém dele, para atestar a gravidade de tal experiência. Há efeitos sociais e culturais ainda não devidamente avaliados que só podem ser mais bem compreendidos no contexto nas lutas por justiça e reparação.

Cada uma dessas consequências impõe investigações ligeiramente distintas, porém é possível articulá-las em torno de um eixo comum quando o que se pretende é a análise crítica sobre os usos e abusos do conceito de trauma no seio das lutas pela memória e, mais especificamente, dos diferentes sentidos desse conceito quando utilizados e praticados por diferentes lugares, campos e atores que protagonizam ou se opõem a essa luta. 
O trauma bem pode figurar como a última fronteira da dor física e psíquica, ou como uma panaceia explicativa, mal definida e imprecisa, que substitui a necessidade de indicar os matizes dessa dor, seu caráter singular e, paradoxalmente, investigações mais profundas sobre o traumático e o caráter retroativo do dano singular. Consequentemente os danos sociais e políticos que se interferem e agem mutuamente na gênese do trauma e do traumático, muitas vezes de formas indiscerníveis, se embaralham na trama de conceitos que os esconde.

\section{O LUTO PROIBIDO E A MELANCOLIA COMO DESTINO}

A presença da melancolia, como caracterização e patrimônio inconteste da literatura romântica do século XVIII, implica que estejam lado a lado a dor e sua expressão; o sublime e o penoso, que forjariam a matéria-prima da escrita romântica. É relevante que o sublime literário esteja tão aliado à dor, como no romantismo, e que a própria condição melancólica tenha se evidenciado como substrato subjetivo de certa disposição da arte, no caso, da literatura. Coisa que, de certo modo, continua presente na literatura contemporânea.

Persiste numa certa definição da melancolia uma suspensão temporal entre o passado e o futuro, uma dor expectante da qual não se pode escapar, mas que adensaria a experiência do presente sofrido e, desse modo, fundaria o sublime (Ginzburg, 2001).

Mesmo assim, a sinalização positiva (sublime) na literatura não frequenta de modo predominante a experiência melancólica. É de um universo de dor e sofrimento que se trata, mas nele subsiste, ou mesmo se define austera - a possibilidade do sublime.

A psicanálise, no início do século XX, com o texto seminal de Freud (1982a) intitulado "Luto e Melancolia", esmerou-se em examinar os processos psíquicos que entram em jogo nas experiências diferenciais do luto e na melancolia. Tal exame tornara-se pos- sível após o surgimento de uma teoria que prometia explicar o psiquismo profundo, sugerindo uma verdadeira investigação que se abriria a partir das proposições de Freud.

Herdeiros do pensamento de Freud e Ferenczi, Nicolas Abraham e Maria Torok (1995) definiram dois processos distintos nas experiências de perda, denominando-os de introjeção e incorporação. No primeiro caso, estamos falando desse trabalho psíquico excelso, que faz reparos e instrui o aparelho psíquico em direção ao seu próprio alargamento e expansão; que permite ao psiquismo, que uma vez se permitiu possuir e ser possuído pelo objeto, num segundo tempo penoso, após a perda do objeto, introjetar as pulsões desligadas sobrantes do objeto e que, ao fazê-lo, o eu se restaure e se expanda tornando-se novamente apto a se aliar a novas e inéditas experiências de investimento amoroso e libidinal.

Lá onde o próprio pensamento atestaria a sua inutilidade residiria o mecanismo que Abraham e Torok denominaram de incorporação, pois é do corpo que se trata, ou da projeção da superfície do corpo que conhecemos como eu (ego), em suma, da recomposição do objeto perdido, do "meu morto", que passa a ser reincorporado como cripta ao próprio eu e arrastado pelo psiquismo. A cripta no seio do eu seria uma miscigenação estranha - tumoral - de uma composição sem dinâmica, exposta a uma intromissão que não admite questionamento. Uma recomposição quase física - ou corpórea, na qual o eu deve caminhar como se doravante carregasse um morto nas costas -, o seu morto que, paradoxalmente, estaria a salvo da morte precisamente aí onde há uma justaposição entre o eu-morto e o seu morto. $\mathrm{O}$ "morto que sou" e que ao mesmo tempo "guardo em mim e para mim", a salvo, mais do que nunca de uma nova perda, cobiça ou desejo de outrem, é o "meu morto" e o "eu-morto" - resguardados e a salvo de ser, mais uma vez, arrancados do eu que os possui.

No conjunto dos elementos indecomponíveis que poderíamos incluir sob o regime
4 A título de exemplo cito o seguinte trecho extraído de uma matéria de um site jornalístico: "'Por mais que saibamos que a polícia está traumatizada-eisso é natural - o que nos preocupa são algumas falas do comando das polícias. Um comandante disse, por exemplo, que $a$ caçada não termina agora, que temosque eliminar. Se há uma reação natural da população, porque todos tiveram seus direitos violados e querem reagir, isso não pode ser aceito por parte do aparato do Estado, especialmente do Comando', afirma Oscar Vilhena. 'Caso embarquem nesse caminho, o Estado não vai se diferenciar dos criminosos. $\mathrm{O}$ que define o crime é a violação da lei, de um lado ou do outro. Esse tipo de retórica abre espaço para que os maus policiais comecem a agir por conta própria', diz". Oscar Vilhena chama a atenção para a correlação entre o sentir-se traumatizado e uma pretensa autorização para a eliminação e a violência, que se torna implícita. Estar traumatizado - seja lá o que isso signifique - autorizaria a reação violenta. Disponível em: http://www.cartamaior.com.br/templates/materiaMostrar.cfm?materia $i d=11166$. Data de acesso: $20 / 5 / 2013$. 
da memória, permanece um calabouço, um lugar de mutismo e silêncio que teríamos que obrigatoriamente reconhecer como aquilo que fora para sempre perdido. Ou seja, entre a ideia de introjeção e incorporação, permanece algo que ainda não foi devidamente pensado e compreendido, e teria mesmo permanecido calado para a teoria e para a clínica psicanalíticas.

Trata-se daquilo que fora perdido para sempre e de uma vez por todas, e não pode ser recuperado, nem reparado, nem substituído. A experiência da perda não nega que, longe da melancolia, o sujeito que perdeu não esquece e que os novos e inéditos objetos acolhidos com hospitalidade e interesse verdadeiro não são substitutos daqueles outros que se foram, se perderam ou que o próprio sujeito admitiu perder. Vemos aí claramente que algo permaneceu latente e não pensado por Freud (Allouch, 2004)

Existe, como quer Allouch (2004), algo que se perde de si - isso que não pertence a ninguém porque é de todos; existia como totalidade compartida, e como coisa fraturada deixa de existir como tal. Seus despojos, pedaços, já não são a própria coisa, talvez, relíquia.

De todo modo, esse algo que se foi é, frequentemente, o traço mais vivo da memória e sua parte mais íntegra. As coisas das quais me lembro com saudade e que permanecem arquivadas, prontas para ser reimpressas (Derrida, 2001), correspondem ao nosso arquivo pessoal. Aquelas coisas que revivemos a partir da percepção (um cheiro, uma música, um déjà-vu, uma experiência tátil) que restaura uma experiência vivida e guardada em arquivo e que por muito pouco não nos reconduz, por via onírica, àquilo que já não existe mais e que, no entanto, jamais deixará de existir.

A desmaterialização perceptiva das pessoas e experiências fundamentais poderá dar lugar à experiência da saudade ou da esperança (Minkowski, 1973). Tal como na despedida de duas pessoas queridas numa estação, atenuada pelo abraço antes da partida, que logo é substituído pelos passos daquele que caminha ao lado do trem, que inicia lentamente sua marcha. Em seguida, o caminhar é substituído pelos olhares, entre quem fica e quem parte, enquanto o trem se distancia e até que o último vagão desapareça. Por fim, após o desaparecimento de qualquer outro vestígio de quem parte e do trem, os trilhos do trem vazios já não são compatíveis com a experiência vivida que ainda se deseja preservar. Nesse momento, a experiência de despedida se converte em esperança e saudade.

Essa breve descrição inspirada no trabalho de Minkowski (1973) revela aquilo que uma infinitude de experiências, filmes e livros não se cansam de mostrar e descrever, e destaca essa passagem ao mesmo tempo lúcida e onírica, pautada claramente pelo desejo de rememorar e preservar aquilo que não existe mais, e que a experiência da saudade (e da esperança) exemplifica de modo tão difuso e impreciso quanto inequívoco.

Mas é preciso pensar ainda naquilo que destrói a possibilidade da experiência da saudade. Isso que nega àquele que perdeu a reimpressão do que foi vivido e qualquer traço de uma experiência impossível de ser presentificada.

Prosseguiremos a partir daqui com o auxílio da releitura de Derrida (2001) sobre a pulsão de morte. Voltemos então àquilo que, para a psicanálise, revelaria a própria destruição da memória, ou que ao menos atacaria a memória de modo peremptório, contínuo e pertinaz: a pulsão de morte.

O exemplo anterior grifa o aspecto erótico da memória e do lembrar, presente na saudade - que só subsiste eroticamente, e isso porque a tarefa da pulsão de morte é o apagamento dos rastros, das pistas, das pegadas e, sob seu auspício e sob sua instrução, que se realize a ordem tirânica que conduz ao apagamento, ao emudecimento, ao desligamento e à repetição.

É aí que reside a diferença entre rememoração e repetição que Freud se esmera em destacar, em 1914, no artigo "Recordar, Repetir e Elaborar". A repetição está longe dos trabalhos da memória, sendo mesmo o 
seu oposto, precisamente porque repetir é o que imanta o sujeito aquém de sua própria história e aquém do tempo vindouro. Ela é a incorporação de um tempo sem tempo e por isso destrói a possibilidade do arquivo. Ela o faz porque o arquivo é o que se guarda para o futuro, para a posteridade e, ao mesmo tempo, é a única resposta à pergunta sobre a verdade - ainda que essa resposta seja sempre imperfeita e lacunar.

Qual é a verdade? Evidentemente a verdade não é algo que se alcança, mas algo que se procura. A busca da verdade - acompanhada da sinceridade - é o que faz da verdade não um ponto de chegada e encerramento, mas ponto a partir do qual, e somente a partir do qual, algo principia 5 .

É nesse sentido que a pulsão de morte é, para Derrida (2001), arquiviolítica: ela destrói, carcome os arquivos na medida em que supõe por encerrado algo que jamais terá fim.

Extraída em boa parte das experiências dos escritores do século XVIII, a melancolia freudiana não deixa de ser romântica, precisamente no sentido de restituição e restauração que carrega, ou seja, a possibilidade de que, uma vez atravessado o luto, o psiquismo estaria apto para novas experiências libidinais e eróticas - novas experiências de amor. Allouch (2004) desconfia dessa restauração freudiana e indica processos outros que iluminam as formas coletivas do luto como formas coletivas da perda.

$\mathrm{O}$ que sancionaria o luto? Ou o que lhe colocaria um termo ${ }^{6}$ ?

Quando convocamos as experiências de luto e perda nas experiências de graves violações, não é o sublime que encontramos, porém é o sublime que procuramos. Um indício, um sinal de que o sujeito sobreviverá ao próprio sofrimento e não sucumbirá a ele. Que se restaurará, como na literatura, um lugar em si, para a linguagem e para o próprio devir. Que não será o trauma o efeito de uma experiência de perda.

Esse ponto de tangenciamento, possível, entre o trauma e a perda não pode e não deve permitir miscigenações impróprias, mas possibilitar que se discrimine com apuro os muitos processos em jogo nas experiências violentas, que de modo algum se esgotam na experiência do trauma.

\section{LEMBRAR E ESQUECER E O HORIZONTE DA MEMÓRIA FELIZ}

Uma das zonas mais incertas e obscuras no campo das lutas pela memória é a dialética da lembrança e do esquecimento. Esquecer, em determinados contextos de luta, militância e reflexão tornou-se indesejável, malvisto, politicamente incorreto. $\mathrm{O}$ esquecimento sofreu de uma fratura perigosa, cuja consequência foi a dicotomia: ou lembrar ou esquecer.

Isso sobrecarregou o dever de lembrar com as expectativas mais promissoras nas lutas pela memória e tem sido considerado a sua maior conquista; mesmo que se saiba que lembrar sempre pode ser tão dramático e insuportável quanto esquecer.

Pensadores contemporâneos (Ricoeur, 2007; Blanchot, 2007) problematizaram essa dicotomia tão simplista como alienante, mas essa problematização ainda não acompanhou as lutas pela memória que ainda hesitam diante da experiência subjetiva do esquecimento.

$\mathrm{O}$ desejo de esquecer, por um lado, presente na própria constituição e possibilidade dos arquivos (Derrida, 2001a), e, por outro, o esquecimento como uma possibilidade subjetiva inconteste e producente, fértil para o horizonte da lembrança, seriam impossíveis sem que o lembrar fosse aquela experiência que restitui ao esquecimento a última fronteira ante o desaparecimento. Todavia, no interior das chamadas lutas pela memória, ao esquecimento ainda são atribuídas as proposições mais radicais de alienação, emudecimento e apagamento. Portanto, é aliado das violências e dos violentos. Em parte porque a defesa do esquecimento aparece frequentemente na prática discursiva de perpetradores e defensores de práticas violentamente autoritárias, que imaginam poder fazer desaparecer com o sentido histórico do esquecimento, banalizando-o e confundindo-o com
5 Algumas das críticas atuais aos trabalhos da Comissão da Verdade no Brasil, iniciados em 2012, recaem sobre o pressuposto de que só conheceremos o conteúdo dos trabalhos da comissão quando o relatório final estiver concluído. Isso indi caria que teremos uma resposta caba a uma infinidade de documentos, fatos testemunhos, depoimentos e arquivos ocultados, omitidos e jamais encontra dos ao final de dois anos de trabalho da comissão. A crítica que a comissão tem sofrido reivindica que se dispare o processo de publicização dos resultados, sejam eles incompletos imperfeitos, parciais ou lacunares. Que se permita que a sociedade brasileira como um todo, e cada sujeito em particular se ponha em busca dessa verdade social pessoal ou nacional desde já impedindo que, doravante, seencerrem os trabalhos de busca da verdade de certo modo, mais fundamentais do que a própria verdade.

6 Ver, a esse respeito, Rousseaux, 2013. 
eliminação pura e simples, ou ainda como mentira histórica: "Vamos esquecer o passado", "não vamos abrir feridas antigas", "não vamos mexer com o que está quieto".

É preciso considerar que o abuso cometido contra o esquecimento se deve, em boa parte, a esses usos impróprios, tributários do medo da atribuição de responsabilidades por crimes, violações e violências cometidas no passado. Diz Ricoeur (2007, p. 423): “[...] é como dano à confiabilidade da memória que o esquecimento é sentido. Dano, fraqueza, lacuna. Sob esse aspecto a memória se define, pelo menos numa primeira instância, como luta contra o esquecimento".

É preciso, contudo, não abandonar o conceito de esquecimento no limbo de seu uso ideologicamente instruído, porque isso poderia conduzir a situações insolúveis e caminhos sem saída, já que não é possível, nem desejável, tudo lembrar.

Freud (1982) chama a atenção para uma impropriedade, precisamente na dinâmica da memória, entre o lembrar e o esquecer. Ele descreve o fenômeno da lembrança difícil, que se manifesta no sintoma como lembrança insidiosa ou lembrança encobridora, e que ocorre para impedir a recordação, mas também para impedir o esquecimento. Desse modo as lembranças encobridoras, como mecanismo de defesa da própria análise, seriam o exemplo de um ataque à memória, já que não se trataria de rememorar coisa alguma, mas de manter uma zona de indistinção entre o que não se pode lembrar e o que não se pode esquecer, obturando assim a experiência temporal constituinte da memória.

Essa zona cinzenta que se constitui como a impossibilidade de lembrar o que não pode ser esquecido (Freud, 1982) revela-se como um ataque à memória, não apenas porque $\mathrm{a}$ dinâmica lembrar e esquecer é impedida, mas porque ela é transformada em outra coisa suportada por uma série infinita de interjogos, repletos de falhas, claudicâncias, hiatos que promovem um entrechoque entre coisas pulsionais desligadas; nem lembradas, nem esquecidas e, portanto, em perpétua tensão cujo efeito é a paralisia e a repetição.
O que Freud (1982, p. 1.683) entende como a tarefa da análise ou da interpretação - " [...] a supressão das lacunas do recordado; dinamicamente o vencimento das resistências do recalque" - indica que o que impede o exercício da memória são os vazios lacunares que impossibilitam que a experiência seja patrimônio da vida consciente onde transitam o esquecer e o lembrar.

O recalcado não é, portanto, o esquecido, mas aquilo que pode ser restaurado apenas de forma lacunar precisamente porque se trata de algo que se repete, porque não pode ser lembrado e nem esquecido (Freud, 1982). Essa impossibilidade simultânea, de lembrar e esquecer, é o que Freud descreve como repetição. $\mathrm{O}$ analisando como aquele que sofre e repete ao invés de recordar.

Desse modo poderíamos dizer que, para Freud, a memória é uma possibilidade que se inscreve na vida consciente, porque o que se combate no recalque é o pleno exercício da memória aprisionada pelos ditames da repetição; repetição de algo que não pode ser esquecido e nem lembrado, deslocado que fora para o limbo atemporal do instante. "[...] podemos dizer que o analisando não recorda nada do esquecido ou reprimido senão que o vive de novo e eternamente" (Freud, 1982, p. 1.684).

Nisso a definição de Blanchot (2007) não é diferente. O esquecimento é o deslocamento do lembrável para uma zona inapagável, evocável, lá onde o lembrável é guardado para garantir seu apagamento e, ao mesmo tempo, protegido de seu radical desaparecimento.

Nesse sentido o esquecimento não é, também em Freud, a indiferença, a aniquilação e o recalcamento, mas a suspensão a um estado de silêncio que, no entanto, é incapaz de colapsar o que poderia - ou deveria - ser lembrado.

Há no esquecimento um dever de memória, um princípio ético que contribui para fundar a noção de história arquivada e reconstruída. Na palavra esquecida, apoderamo-nos do espaço a partir do qual ela fala e que agora nos remete ao sentido mudo, indis- 
ponível e sempre latente como possibilidade de lembrar (Blanchot, 2007).

Portanto, os denominados locais de memória (Assman, 2011), como locais estáticos por sua própria natureza física e imóvel, apontam "[...] para a possibilidade de que os locais possam tornar-se sujeitos, portadores de recordação e possivelmente dotados de uma memória que ultrapassa amplamente a memória dos seres humanos" (Assman, 2011, p. 317). Neles parece ser assegurada, ao mesmo tempo, a possibilidade de lembrar e a possibilidade de esquecer e indicada a impossibilidade de tudo lembrar e de tudo esquecer. De muitas maneiras, neles, estaria assegurado o dever de lembrar.

Portanto, o debate ético que os memoriais permitem é fundador. Ao se "ancorarem no chão" (Assman, 2011, p. 318), o que se inaugura é a possibilidade de lembrar e não, necessariamente, a injunção de lembrar. Os locais de memória aguardam e mesmo exigem algum esforço, um deslocamento físico até os locais de memória e seus arquivos. Eles esperam, em latência, por aqueles que desejam lembrar.

Podemos lembrar, nos memoriais e nos acervos, do que gostaríamos de lembrar ou do que gostaríamos de esquecer. Ir a um memorial ou perscrutar um acervo é ao mesmo tempo uma luta íntima, em boa parte desconhecida, que coloca em xeque a difícil inscrição do sujeito em sua própria história a partir do encontro com histórias que, ao mesmo tempo, o ultrapassam e lhe pertencem.

A peregrinação aos memoriais revelaria, então, um pacto renovado com a memória: se quisermos, podemos lembrar e, depois, podemos esquecer. $\mathrm{O}$ esquecimento aqui não seria coevo, análogo ou efeito da destruição e da eliminação. Pode-se esquecer, porque os memoriais ainda estarão lá, fisicamente insistentes e ancorados, para nos fazer lembrar. Zeladores que são da preservação da dialética do lembrar e do esquecer e, como tais, da celebração inconteste da memória, não apenas porque permitem lembrar, mas também porque possibilitam esquecer.
Esquecer sem culpa e lembrar com saudades se anuncia no horizonte de uma memória feliz.

Isso que vemos em muitas lutas políticas em torno da memória sofre de uma imprecisão, e mesmo de um erro conceitual que aturde e atrapalha. Não se trataria, portanto, de luta contra o esquecimento, mas da impossibilidade da ruína da experiência do lembrar e do esquecer sempre que se sugere um recalcamento eterno, alojando o esquecido não no passado, mas fora do tempo e da história e exilado da linguagem para sempre.

Como sugere Ricoeur (2007, p. 435): “o esquecimento pode estar tão estreitamente confundido com a memória, que pode ser considerado uma de suas condições". E o que atesta de modo inequívoco essa intrincação é a experiência do reconhecimento como experiência da memória fundadora, que reconhece e faz existir, em oposição à memória destruidora, que apaga os rastros e se interpõe entre o reconhecimento e seus traços.

"Esse reconhecimento pode assumir diferentes formas. Ele já se produz no decorrer da percepção: um ser esteve presente uma vez; ausentou-se; voltou. Aparecer-desaparecer-reaparecer. Nesse caso, o reconhecimento ajusta - ajunta - o reaparecer ao aparecer por meio do desaparecer" (Ricoeur, 2007, p. 437).

O reconhecimento é a experiência feliz de que aquilo que nos permitiu reconhecer é o indicador de que algo permaneceu vivo em nós e, como vivo, retorna. Poderíamos dizer, um tanto provisoriamente, que assim como a melancolia é a experiência da presença sempiterna do morto, o reconhecimento é a experiência do reencontro com o vivo. Reencontro entre dois traços de vida que perduram prestes a gerar uma experiência psíquica saborosa propiciada pelo reaparecimento: o reconhecimento.

O esquecimento permanece enigmático, por vezes maldito, e um tanto estrangeiro, tanto nas lutas pela memória como nas teorias que as reconhecem. Importante debate no contexto das consequências éticas das lutas que percorrem um pensamento em torno da memória. 


\section{BIBLIOGRAFIA}

ABRAHAM, Nicolas; TOROK, Maria. A Casca e o Núcleo. Tradução de Maria José Coracinil. São Paulo, Escuta,1995.

AGAMBEN, Giorgio. Lo que Queda de Auschwitz: el Archivo y el Testigo. Madrid, Pre-Textos, 2005.

ALLOUCH, Jean. Erótica do Luto no Tempo da Morte Seca. Tradução de Procópio Abreu. Rio de Janeiro, Companhia de Freud, 2004.

ASSMAN, Aleida. Espaços da Recordação: Formas e Transformações da Memória Cultural. Tradução de Paulo Soethe. Campinas, Editora da Unicamp, 2011.

BLANCHOT, Maurice. A Conversa Infinita 2. Tradução de João Moura Jr. São Paulo, Escuta, 2007.

BURNETT, Angela; THOMPSON, Kate. "A Melhora do Bem-estar Psicossocial de Refugiados e Pessoas que Buscam Asilo", in Paulo Endo et alii (orgs.). Psicologia, Violência e Direitos Humanos. São Paulo, CRP06, 2011, pp. 22-55.

DERRIDA, Jacques. Estados da Alma da Psicanálise: o Impossivel para Além da Soberana Crueldade. Tradução de Isabel Khan Marin et al. São Paulo, Escuta, 2001. . Mal de Arquivo: uma Impressão Freudiana. Tradução de Claudia Moraes Rego.

Rio de Janeiro, Relume-Dumará, 2001a.

ENDO, Paulo. “Elaboração Onírica, Sonhos Traumáticos e Representação na Literatura de Testemunho Pós-ditadura no Brasil", in Marcio Seligman-Silva, Jaime Ginzburg e Francisco Foot Hardman (orgs.). Escritas da Violência. Vol. 1. Rio de Janeiro, 7 Letras, 2012, pp.119-32.

FELMAN, S.; LAUB, Dori. Testimony: Crises of Witnessing in Literature, Psychoanalysis and History. New York, Routledge, 1992.

FREUD, Sigmund. "Recuerdo, Recordación y Elaboración", in Obras Completas de Sigmund Freud. T. II. Madrid, Biblioteca Nueva, 1982, pp. 1.683-8.

"Duelo y Melancolia", in Obras Completas de Sigmund Freud. T. II. Madrid, Biblioteca Nueva, 1982a, pp. 2.091-100.

GINZBURG, Jaime. "Conceito de Melancolia", in Revista da Associação Psicanalítica de Porto Alegre/Associação Psicanalítica de Porto Alegre, no 20, 2001, pp. 102-16.

LEYS, Ruth. "Death Masks: Kardiner and Ferenczi on Psychic Trauma", in Representatitons, no 53/Winter, 1996, pp. 44-73.

MINKOWSKI, Eugene. El Tiempo Vivido: Estudos Fenomenológicos e Psicopatológicos.

Tradução de Angel Sáiz Sáez. México, Fondo de Cultura Económica,1973.

RAUTER, Cristina et alii (orgs.). Clínica e Política: Subjetividade e Violação de Direitos Humanos. Rio de Janeiro, Instituto Franco Basaglia/ Tecorá, 2002.

RICOEUR, Paul. A Memória, a História, o Esquecimento. Tradução de Alain François et al. Campinas, Editora da Unicamp, 2007.

ROUSSEAUX, Fabiana. Sancionar el Duelo. Desaparición, Duelo y Impunidad. El Caso Argentino. Disponível em: http://www.herreros.com.ar/melanco/rousseaux.htm. Acesso em: 20/5/2013.

SCARRY, Elaine. Body in Pain: Making and Unmaking of the World. New York, Oxford University Press, 1985.

SELIGMAN-SILVA, Marcio; GINZBURG, Jaime; HARDMAN, Francisco Foot (orgs.). Escritas da Violência. Vol. 1. Rio de Janeiro, 7 Letras, 2012.

TELES, Janaina de Almeida; TELES, Edson; SANTOS, Cecilia (orgs.). Desarquivando a Ditadura: Memória e Justiça no Brasil. São Paulo, Aderaldo e Rotschild, 2009. 